\title{
Predictive Factors for Completion of TPF Induction Chemotherapy in Patients With Locally Advanced Head and Neck Cancer
}

\author{
KENJI NAKANO ${ }^{1}$, AKIRA SETO ${ }^{2}$, TORU SASAKI ${ }^{2}$, WATARU SHIMBASHI ${ }^{2}$, HIROFUMI FUKUSHIMA ${ }^{2}$, \\ HIROYUKI YONEKAWA ${ }^{2}$, HIROKI MITANI ${ }^{2}$ and SHUNJI TAKAHASHI ${ }^{1}$ \\ ${ }^{I}$ Department of Medical Oncology, Cancer Institute Hospital of the \\ Japanese Foundation for Cancer Research, Tokyo, Japan; \\ ${ }^{2}$ Department of Head and Neck Surgery, Cancer Institute Hospital of the \\ Japanese Foundation for Cancer Research, Tokyo, Japan
}

\begin{abstract}
Background: Induction therapy with docetaxel, cisplatin and fluorouracil (TPF) is a treatment option for locally advanced head and neck cancer (LAHNC), but it is not known which patients are appropriate for TPF. Patients and Methods: We retrospectively reviewed the records of patients with LAHNC who underwent induction TPF, and evaluated factors predictive of the completion of TPF treatment (defined as $\geq 3$ cycles administered). Results: Of the total 93 enrolled patients, 73 (78.5\%) achieved therapy completion. In a multivariate analysis, hypolaryngeal/ laryngeal primary tumor site was a negative predictive factor (hazard ratio $(H R)=0.32,95 \%$ confidence interval $(C I)=0.11-0.96, p=0.041)$ and body mass index $\geq 22$ $\mathrm{kg} / \mathrm{m}^{2}$ was a positive predictive factor (hazard ratio $=3.51,95 \%$ confidence intervaI $=1.04-11.83, p=0.043)$ of TPF completion. Conclusion: For patients with $L A H N C$, oropharyngeal primary tumor site and high body mass index can be used to predict TPF completion and may contribute to decisions on the indications for TPF in terms of safety and tolerability.
\end{abstract}

Head and neck cancer accounts for $4 \%$ of malignant diseases, and $25-50 \%$ of individuals with head and neck cancer first present neck swelling and are diagnosed as having disease at a locally advanced stage with neck lymph node metastases (1). Locally advanced head and neck cancer (LAHNC) needs multidisciplinary treatments, including surgical resection, radiation therapy, and systemic chemotherapy. For surgically unresectable LAHNC and in

Correspondence to: Dr. Kenji Nakano, Dept. of Medical Oncology, Cancer Institute Hospital, Japanese Foundation for Cancer Research, Ariake, Tokyo 135-0063, Japan. Tel: +81 335200111, Fax:+81335200141, e-mail: kenji.nakano@jfcr.or.jp

Key Words: Head and neck cancer, induction chemotherapy, docetaxel, cisplatin, fluorouracil. those who desire the preservation of organ functions such as speech and swallowing, non-surgical treatment strategies are important, and induction chemotherapy is one such nonsurgical treatment option (2). The TPF chemotherapy regimen comprising docetaxel, cisplatin and fluorouracil is the most effective regimen for induction chemotherapy administered to patients with LAHNC (3), but its clinical role compared to other non-surgical treatment options, especially concurrent chemoradiotherapy (CRT), has not been established because the several randomized control trials that compared the efficacy of induction TPF and CRT with platinum-based chemotherapy showed no superiority of induction TPF over CRT (4).

Regarding safety, many adverse events including myelosuppression, gastrointestinal events, neurotoxicity, and nephrotoxicity, are expected to be observed during TPF treatment, and some patients fail to complete the targeted cycles of TPF, usually set at three cycles. In clinical practice, predictive markers evaluating the indications for TPF in terms of efficacy and safety are needed. In this retrospective study, we attempted to identify predictive factors of TPF completion by analyzing the clinical data of patients with LAHNC who underwent TPF treatment.

\section{Patients and Methods}

We retrospectively reviewed the clinical records of patients with LAHNC who received induction chemotherapy with the TPF regimen at our hospital. Patients with nasopharyngeal cancer and cancer with unknown primary (CUP) site located at neck lymph nodes were included. Patients who received any antitumor treatment before TPF or received induction chemotherapy other than TPF were excluded.

The induction TPF regimen consisted of intravenous infusions of $75 \mathrm{mg} / \mathrm{m}^{2}$ docetaxel on day $1,75 \mathrm{mg} / \mathrm{m}^{2}$ cisplatin on day 1 , and $750 \mathrm{mg} / \mathrm{m}^{2} /$ day 5 -fluorouracil continuous intravenous infusion on days 1-5 every 3 weeks. The indications for induction chemotherapy were 
Table I. Characteristics of the 93 patients with locally advanced head and neck cancer.

\begin{tabular}{|c|c|}
\hline Characteristic & Value \\
\hline \multicolumn{2}{|l|}{ Age, years } \\
\hline Median (range) & $58.2(21-75)$ \\
\hline$\geq 60$ Years, $\mathrm{n}(\%)$ & $40(43.0)$ \\
\hline \multicolumn{2}{|l|}{ Gender, n (\%) } \\
\hline Male & $83(89.2)$ \\
\hline Female & $10(10.8)$ \\
\hline \multicolumn{2}{|l|}{ Smoking history } \\
\hline Present & $69(74.2)$ \\
\hline Absent & $24(25.8)$ \\
\hline \multicolumn{2}{|l|}{ BMI, $\mathrm{kg} / \mathrm{m}^{2}$} \\
\hline Median (range) & $21.7(15.8-30.2)$ \\
\hline$\geq 22.0 \mathrm{~kg} / \mathrm{m}^{2}$ & $41(44.1)$ \\
\hline \multicolumn{2}{|l|}{ Primary site, n (\%) } \\
\hline Oropharynx & $38(40.8)$ \\
\hline Hypopharynx & $20(21.5)$ \\
\hline Larynx & $2(2.2)$ \\
\hline Oral cavity & $13(14.0)$ \\
\hline Paranasal sinus & $4(4.3)$ \\
\hline Nasopharynx & $11(11.8)$ \\
\hline Unknown primary & $5(5.4)$ \\
\hline \multicolumn{2}{|l|}{ T-Stage, n (\%) } \\
\hline 1 & $6(6.5)$ \\
\hline 2 & $16(17.2)$ \\
\hline 3 & $26(27.9)$ \\
\hline 4 & $40(43.0)$ \\
\hline $\mathrm{X}$ & $5(5.4)$ \\
\hline \multicolumn{2}{|l|}{ N-Stage, n (\%) } \\
\hline 0 & $6(6.5)$ \\
\hline 1 & $9(9.7)$ \\
\hline 2 & $61(65.5)$ \\
\hline 3 & $17(18.3)$ \\
\hline
\end{tabular}

BMI: Body mass index.

decided by the hospital's Multidisciplinary Board in which head and neck surgeons, radio-oncologists and medical oncologists participated. We defined 'TPF completion' as the receipt of three cycles of TPF. 'TPF failure' was defined as a change in or the termination of TPF treatment before the accomplishment of three cycles of TPF, regardless of the reason. Dose amendment or treatment delay in each cycle due to adverse events was allowed by physician decision.

The patients' clinical stages were evaluated based on the seventh edition of the American Joint Committee on Cancer classification (5). Adverse events were documented based on the Common Terminology Criteria for Adverse Events (CTCAE) version 4.0 (6). For the evaluation of patient prognosis, overall (OS) and progression-free (PFS) survival were estimated by the KaplanMeier method. Dsease progression was evaluated based on Response Evaluation Criteria In Solid Tumours (RECIST) version 1.1 (7). The log-rank test was used for comparison of prognoses. Response rates were compared by performing logistic regression analysis. Predictive factors of TPF completion or failure were evaluated by Fisher's exact test and logistic regression analysis. For all statistical analyses, SPSS ver. 25.0 software (IBM, Armonk, NY, USA) was used. In all of the analyses, a value of $p<0.05$ was considered significant.
Table II. Subsequent therapy of the 73 patients who completed taxane, platinum and 5-fluorouracil therapy.

\begin{tabular}{lc}
\hline Treatment & No. of patients \\
\hline Concurrent chemoradiation & 42 \\
Cisplatin & 22 \\
Cetuximab & 9 \\
Carboplatin & 1 \\
Docetaxel & 10 \\
Curative surgery & 3 \\
Surgery following radiation & 4 \\
Radiation & 16 \\
None & 8 \\
\hline
\end{tabular}

This retrospective study was approved by the Institutional Review Board of the Cancer Institute Hospital of the Japanese Foundation for Cancer Research (2017-1176).

\section{Results}

From April 2006 to February 2017, a total of 137 patients with LAHNC received TPF induction chemotherapy at our hospital; of them, 44 patients were excluded from the analyses because of recurrent setting $(n=27)$, receiving treatment regimens other than TPF $(n=14)$, and unconfirmed pathological diagnoses $(n=3)$. A final total of 93 patients were enrolled in the present analyses. The patients' characteristics are summarized in Table I. Most of the patients $(89.2 \%)$ were male $(n=83)$, and a smoking history was common (74.2\%). Regarding their primary lesions, $11(12 \%)$ patients with nasopharyngeal cancer and five $(5 \%)$ of those with CUP were included.

TPF completion was achieved by $73(78.5 \%)$ out of the 93 patients with LAHNC, and the median relative TPF dose intensity among those 73 patients was $85.2 \%$ (range $=57.9$ $100 \%)$. The reasons for TPF failure in the other 20 patients were as follows: adverse events $(n=8)$, disease progression $(n=8)$, and other reasons $(n=4)$. The treatments that followed the TPF regimen are summarized in Table II: CRT was selected by 42 (57.5\%) patients, and 22 patients received CRT with cisplatin.

With a median follow-up time of 27.5 (range=1.3-151.1) months, the median PFS considering all 93 patients was 14.0 months (95\% confidence interval=7.4-20.6 months) and the median OS was 36.8 (12.1-61.6) months. Patients who completed the TPF regimen achieved significantly longer PFS and OS compared to those who failed to complete TPF therapy (median PFS: 26.7 vs. 2.3 months, $p<0.0001$; and median OS: 85.9 vs. 6.6 months, $p<0.0001$ ) (Figure 1).

The details of the adverse events observed during the TPF are given in Table III. Adverse events that were observed at $\geq 10 \%$ in patients with TPF failure compared to those who completed TPF were hypoalbuminemia, hypocalcemia, hypokalemia, diarrhea, and infection. Among other adverse 


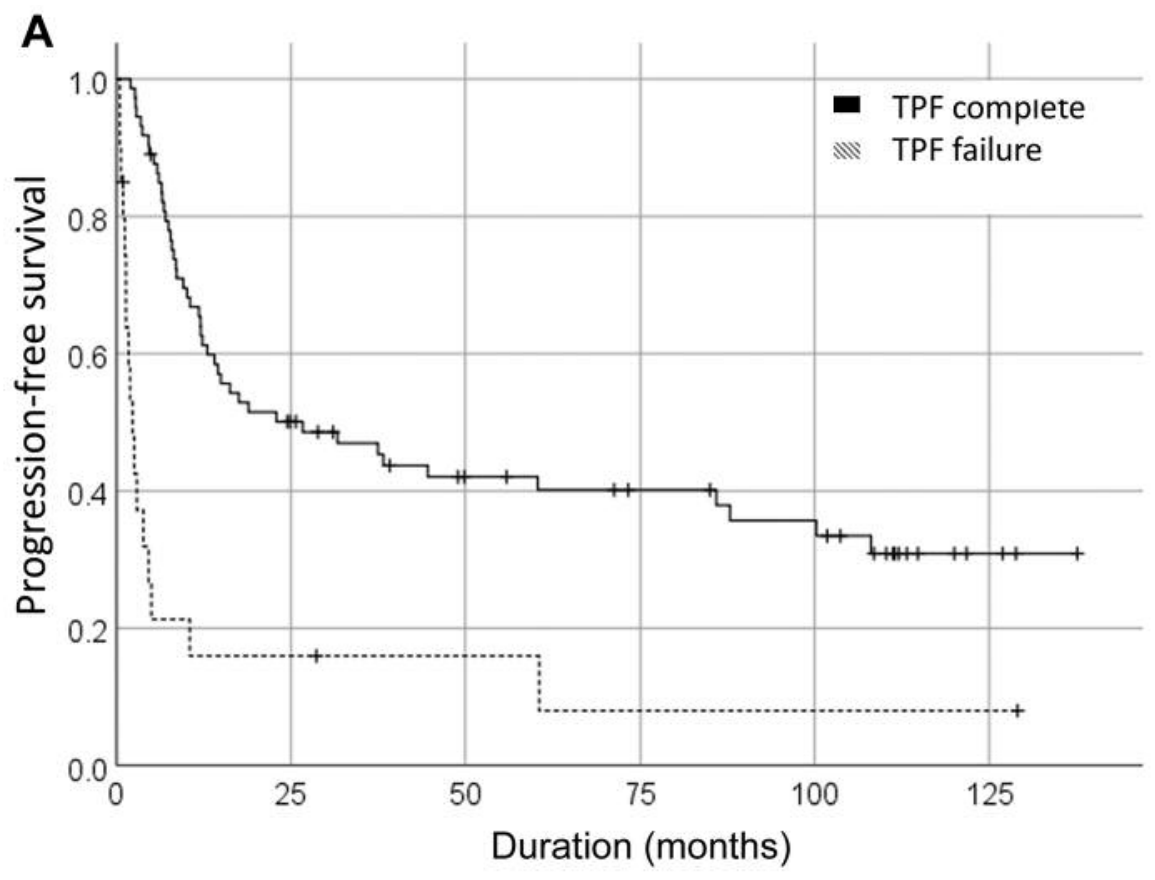

B

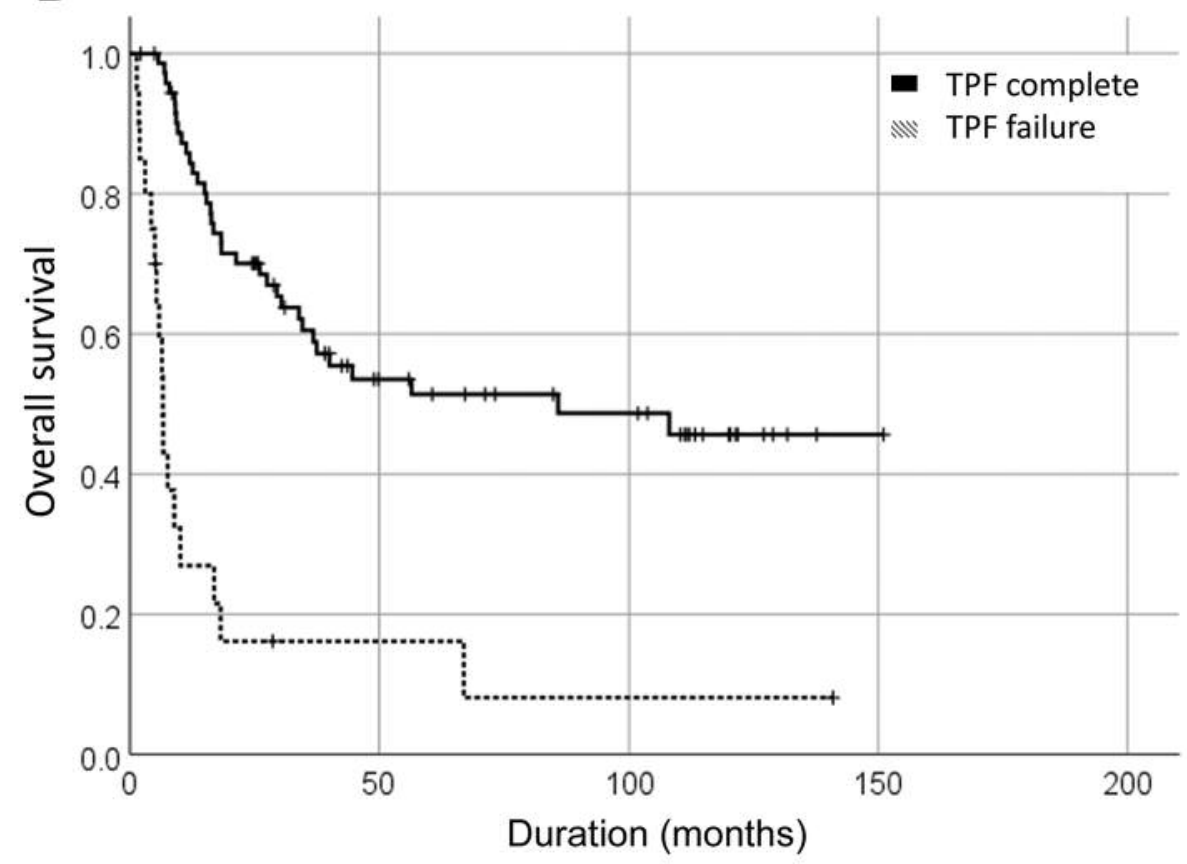

Figure 1. The progression-free (PFS) (A) and overall $(O S)(B)$ survival of patients with locally advanced head and neck cancer who completed and those who failed taxane, platinum and 5-fluorouracil (TPF) therapy. The median PFS of patients who completed TPF therapy was 26.7 months (95\% CI=4.149.3 months; 46 progression events) while it was 2.3 months (95\% CI=1.2-3.5 months; 17 progression events) (log-rank $p<0.0001)$. Corresponding median OS was 85.9 months (95\% CI: not estimated; 34 deaths) and 6.6 months (95\% CI=5.5-7.7 months; 17 deaths), respectively (log-rank $p<0.0001)$.

events, myelosuppression, increased aspartate transaminase/ alanine transaminase, increased serum creatinine, hyponatremia, hyperkalemia, nausea/vomiting, and anorexia were observed in more than half of all patients.
We first evaluated the factors predictive of TPF completion using Fisher's exact test; oropharyngeal primary tumor site, hypolaryngeal/laryngeal primary site and a body mass index (BMI) $\geq 22 \mathrm{~kg} / \mathrm{m}^{2}$ were significant; by odds ratio (OR), the 
Table III. Adverse events of induction taxane, platinum and 5-fluorouracil therapy.

\begin{tabular}{|c|c|c|c|c|c|c|}
\hline \multirow[t]{2}{*}{ Adverse event, n (\%) } & \multicolumn{2}{|c|}{ All patients $(n=93)$} & \multicolumn{2}{|c|}{ TPF completion $(n=73)$} & \multicolumn{2}{|c|}{ TPF failure $(n=20)$} \\
\hline & All grades & Grade $\geq 3$ & All grades & Grade $\geq 3$ & All grades & Grade $\geq 3$ \\
\hline Leukocytopenia & $89(95.7)$ & $63(67.7)$ & $72(98.7)$ & $53(72.6)$ & $17(85.0)$ & $10(50.0)$ \\
\hline Neutropenia & $88(94.6)$ & $77(82.8)$ & $71(97.3)$ & $65(89.0)$ & $17(85.0)$ & $12(60.0)$ \\
\hline Anemia & $91(97.8)$ & $8(8.6)$ & $71(97.3)$ & $5(68.5)$ & $20(100)$ & $3(15.0)$ \\
\hline Thrombocytopenia & $23(24.7)$ & $2(2.2)$ & $17(23.3)$ & $1(1.4)$ & $6(30.0)$ & $1(5.0)$ \\
\hline Hypoalbuminemia & 74 (79.6) & $0(0 \%)$ & $56(76.7)$ & $0(0 \%)$ & $18(90.0)$ & $0(0 \%)$ \\
\hline Serum bilirubin $\uparrow$ & $32(34.4)$ & $1(1.1)$ & $27(37.0)$ & $1(1.4)$ & $5(25.0)$ & $0(0 \%)$ \\
\hline $\mathrm{AST} \uparrow$ & $65(69.9)$ & $1(1.1)$ & $51(69.9)$ & $0(0 \%)$ & $14(70.0)$ & $1(5.0)$ \\
\hline ALT $\uparrow$ & $56(60.2)$ & $2(2.2)$ & 45 (61.6) & $1(1.4)$ & $11(55.0)$ & $1(5.0)$ \\
\hline Serum creatinine $\uparrow$ & $49(52.7)$ & $1(1.1)$ & $41(56.2)$ & $1(1.4)$ & $8(40.0)$ & $0(0 \%)$ \\
\hline Hypocalcemia & $65(69.9)$ & $1(1.1)$ & $47(64.4)$ & $0(0 \%)$ & $18(90.0)$ & $1(5.0)$ \\
\hline Hypercalcemia & $6(6.5)$ & $0(0 \%)$ & $5(6.8)$ & $0(0 \%)$ & $1(5.0)$ & $0(0.0)$ \\
\hline Hyponatremia & $81(87.1)$ & $18(19.4)$ & $63(86.3)$ & $10(13.7)$ & $18(90.0)$ & $8(40.0)$ \\
\hline Hypokalemia & $41(44.1)$ & $8(8.6)$ & $30(41.1)$ & $5(6.8)$ & $11(55.0)$ & $3(15.0)$ \\
\hline Hyperkalemia & $50(53.8)$ & $2(2.2)$ & $39(53.4)$ & $0(0 \%)$ & $11(55.0)$ & $2(10.0)$ \\
\hline Mucositis & $23(24.7)$ & $4(4.4)$ & $20(27.4)$ & $3(4.1)$ & $3(15.0)$ & $1(5.0)$ \\
\hline Nausea/vomiting & $55(59.1)$ & $7(7.5)$ & $42(57.5)$ & $5(6.8)$ & $13(65.0)$ & $2(10.0)$ \\
\hline Anorexia & $56(60.2)$ & $9(9.7)$ & 47 (64.4) & $8(11.0)$ & $9(45.0)$ & $1(5.0)$ \\
\hline Diarrhea & $34(36.6)$ & $7(7.5)$ & $25(34.2)$ & $3(4.1)$ & $9(45.0)$ & $4(20.0)$ \\
\hline Constipation & $19(20.4)$ & $0(0 \%)$ & $19(26.0)$ & $0(0 \%)$ & $0(0 \%)$ & $0(0 \%)$ \\
\hline Infection & $50(53.8)$ & 37 (39.8) & $37(50.7)$ & $28(38.4)$ & $13(65.0)$ & $9(45.0)$ \\
\hline Other & $8(8.6)$ & $2(2.2)$ & $5(6.8)$ & $0(0 \%)$ & $3(15.0)$ & $2(10.0)$ \\
\hline
\end{tabular}

ALT: aspartate transaminase; AST: alanine transaminase.

Table IV. Analysis of predictive factors for taxane, platinum and 5-fluorouracil therapy completion.

\begin{tabular}{|c|c|c|c|c|c|c|}
\hline \multirow[t]{2}{*}{ Variable } & \multicolumn{3}{|c|}{ Fisher's exact test } & \multicolumn{3}{|c|}{ Logistic regression analysis } \\
\hline & OR & $95 \% \mathrm{CI}$ & $p$-Value & OR & $95 \% \mathrm{CI}$ & $p$-Value \\
\hline Male sex & 1.66 & $0.39-7.14$ & 0.444 & - & & - \\
\hline Smoking history & 1.77 & $0.61-5.16$ & 0.387 & - & - & - \\
\hline Age, $\geq 60$ years & 0.90 & $0.33-2.44$ & $>0.99$ & - & - & - \\
\hline $\mathrm{BMI} \geq 22 \mathrm{~kg} / \mathrm{m}^{2}$ & 4.11 & $1.25-13.49$ & 0.021 & 3.51 & $1.04-11.83$ & 0.043 \\
\hline T-Stage 4 & 2.03 & $0.70-5.88$ & 0.212 & - & - & - \\
\hline N-Stage 3 & 0.41 & $0.13-1.31$ & 0.188 & - & - & - \\
\hline \multicolumn{7}{|l|}{ Primary lesion: } \\
\hline Nasopharynx & 3.02 & $0.36-25.10$ & 0.446 & - & - & - \\
\hline Oral cavity/paranasal sinus & 0.87 & $0.25-3.02$ & 0.756 & - & - & - \\
\hline Oropharynx & 3.49 & $1.06-11.44$ & 0.041 & - & - & - \\
\hline Hypopharynx/larynx & 0.27 & $0.09-0.77$ & 0.017 & 0.32 & $0.11-0.96$ & 0.041 \\
\hline Unknown primary & 0.39 & $0.06-2.48$ & 0.292 & - & - & - \\
\hline
\end{tabular}

presence of a hypolaryngeal/laryngeal primary was considered a factor with a negative influence on TPF completion, and oropharyngeal primary site and $\mathrm{BMI} \geq 22 \mathrm{~kg} / \mathrm{m}^{2}$ were considered positive factors.

We then evaluated these three factors in a logistic regression analysis, and hypolaryngeal/laryngeal primary tumor site and $\mathrm{BMI} \geq 22 \mathrm{~kg} / \mathrm{m}^{2}$ retained significance as factors of TPF completion (Table IV).

\section{Discussion}

Many randomized clinical trials that compared induction chemotherapy and CRT have been performed, but most of these trials did not show superiority of the induction chemotherapy (8-10). The optimal treatment modality and subsequent induction chemotherapy have also not been established; e.g. radiation only, CRT, or concomitant 
radiotherapy with cetuximab (i.e. bioradiotherapy). There is clinical evidence that bioradiotherapy after the completion of a TPF regimen was non-inferior to CRT in selected patients (with laryngeal cancer) (11), but another study did not show its superiority to CRT (12).

In clinical practice, despite the limited clinical evidence, induction chemotherapy has been administered to patients with LAHNC whose tumors have grown so rapidly that there was no time to design definitive radiation therapy, and to patients who were expected to receive benefits from chemo-selection by induction chemotherapy (13). In such limited settings, however, the factors that are predictive of patient feasibility for or tolerance of induction chemotherapy are not known.

The results of our present retrospective analyses indicate that a patient's BMI and the site of the primary lesion affect the likelihood of completing a TPF regimen. The BMI is influenced by many factors (e.g. the patient's nutrition status, muscle mass, and total doses of antitumor drugs used), and it will thus be a challenge to identify the precise mechanism whereby the BMI affects the likelihood of TPF completion. However, the BMI is easy to measure in daily practice and thus might be useful for the prediction of TPF completion.

Our analyses also suggest that the primary lesion may be predictive of TPF completion. Clinical trials of induction chemotherapy targeted to patients with nasopharyngeal and oropharyngeal cancer have shown high clinical benefits (14, 15), whereas a trial of induction chemotherapy for patients with hypopharyngeal/laryngeal cancer has not (16); these results might be due to differences in tumor response at different primary sites. The clinical significance of induction chemotherapy should be evaluated in future studies based on subdivided primary sites: Nasopharyngeal, oropharyngeal, hypopharyngeal/laryngeal, and CUP.

Our study has several limitations: Its non-comparative design, and the enrollment of patients with LAHNC regardless of their primary lesions (including nasopharyngeal cancer and CUP), which made it difficult to evaluate the clinical benefits of the TPF regimen in terms of efficacy. The lack of human papillomavirus status among the patients with oropharyngeal cancer also made it difficult to evaluate TPF treatment efficacy. In our analyses, the administration of three cycles was defined as completion of TPF, but the early response evaluation of induction chemotherapy by endoscopy or positron-emission tomography/computed tomography was recently proposed (17). Changes in the number of treatment cycles based on the patient's response or tolerability at each cycle might contribute to the goal of maximizing the clinical benefit of induction chemotherapy but our study did not take this into consideration.

In conclusion, the use of the patient's BMI and primary tumor site might contribute to decisions regarding whether to administer induction TPF to a patient with LAHNC. Incorporating this clinical information will help clinicians select the appropriate patients for induction TPF and maximize the clinical benefits of the treatment for LAHNC.

\section{Conflicts of Interest}

None to declare.

\section{Authors' Contributions}

Conception and design: KN; Article writing: KN; Final approval: KN, AS, TS, WS, HF, HY, HM, ST; Patient management: KN, AS, TS, WS, HF, HY, HM, ST. All Authors read and approved the final article.

\section{Acknowledgements}

The Authors thank all the staff members of the Departments of Medical Oncology and Head and Neck Surgery at the Cancer Institute Hospital of the Japanese Foundation for Cancer Research for diagnosing and treating the patients enrolled in this study.

\section{References}

1 DeVita VT Jr., Lawrence TS and Rosenberg SA: DeVita, Hellman, and Rosenberg's Cancer Principles \& Practice of Oncology 11th Edition. Philadelphia: Wolters Kluwer 2018.

2 Haddad RI, Posner M, Hitt R, Cohen EEW, Schulten J, Lefebvre $\mathrm{JL}$ and Vermorken JB: Induction chemotherapy in locally advanced squamous cell carcinoma of the head and neck: Role, controversy, and future directions. Ann Oncol 29(5): 1130-1140, 2018. PMID: 29635316. DOI: 10.1093/annonc/mdy102.

3 Blanchard P, Bourhis J, Lacas B, Posner MR, Vermorken JB, Cruz Hernandez JJ, Bourredjem A, Calais G, Paccagnella A, Hitt R, Pignon JP; Meta-Analysis of Chemotherapy in Head and Neck Cancer, Induction Project, Collaborative Group. Taxanecisplatin-fluorouracil as induction chemotherapy in locally advanced head and neck cancers: An individual patient data meta-analysis of the Meta-analysis of Chemotherapy in Head and Neck Cancer Group. J Clin Oncol 31(23): 2854-2860, 2013. PMID: 23835714. DOI: 10.1200/JCO.2012.47.7802.

4 Budach W, Bölke E, Kammers K, Gerber PA, Orth K, Gripp S and Matuschek $\mathrm{C}$ : Induction chemotherapy followed by concurrent radio-chemotherapy versus concurrent radiochemotherapy alone as treatment of locally advanced squamous cell carcinoma of the head and neck (HNSCC): A meta-analysis of randomized trials. Radiother Oncol 118(2): 238-243, 2016. PMID: 26589131. DOI: 10.1016/j.radonc.2015.10.014.

5 Edge SB, Byrd DR, Compton CC, Fritz AG, Greene FL, Trotti A (eds.): AJCC Cancer Staging Manual (Seventh Edition). New York, NY: Springer; 2010.

6 National Cancer Institute. Common Terminology Criteria for Adverse Events (CTCAE), Version 4.03. National Cancer Institute. 2010. (Online). Available at: http://evs.nci.nih.gov/ftp1/CTCAE/ CTCAE_4.03_2010-06-14_QuickReference_5x7.pdf

7 Eisenhauer EA, Therasse P, Bogaerts J, Schwartz LH, Sargent D, Ford R, Dancey J, Arbuck S, Gwyther S, Mooney M, Rubinstein L, Shankar L, Dodd L, Kaplan R, Lacombe D and Verweij J: New Response Evaluation Criteria in Solid Tumours: Revised RECIST guideline (version 1.1). Eur J Cancer 45(2): 228-247, 2009. PMID: 19097774. DOI: 10.1016/j.ejca.2008. 10.026. 
8 Haddad R, O’Neill A, Rabinowits G, Tishler R, Khuri F, Adkins D, Clark J, Sarlis N, Lorch J, Beitler JJ, Limaye S, Riley S and Posner M: Induction chemotherapy followed by concurrent chemoradiotherapy (sequential chemoradiotherapy) versus concurrent chemoradiotherapy alone in locally advanced head and neck cancer (PARADIGM): A randomised phase 3 trial. Lancet Oncol 14(3): 257-264, 2013. PMID: 23414589. DOI: 10.1016/S1470-2045(13)70011-1.

9 Hitt R, Grau JJ, López-Pousa A, Berrocal A, García-Girón C, Irigoyen A, Sastre J, Martínez-Trufero J, Brandariz Castelo JA, Verger E, Cruz-Hernández JJ; Spanish Head and Neck Cancer Cooperative Group (TTCC): A randomized phase III trial comparing induction chemotherapy followed by chemoradiotherapy versus chemoradiotherapy alone as treatment of unresectable head and neck cancer. Ann Oncol 25(1): 216-225, 2014. PMID: 24256848. DOI: 10.1093/annonc/mdt461.

10 Cohen EE, Karrison TG, Kocherginsky M, Mueller J, Egan R, Huang CH, Brockstein BE, Agulnik MB, Mittal BB, Yunus F, Samant S, Raez LE, Mehra R, Kumar P, Ondrey F, Marchand P, Braegas B, Seiwert TY, Villaflor VM, Haraf DJ and Vokes EE: Phase III randomized trial of induction chemotherapy in patients with N2 or N3 locally advanced head and neck cancer. J Clin Oncol 32(25): 2735-2743, 2014. PMID: 25049329. DOI: 10.1200/JCO.2013.54.6309.

11 Lefebvre JL, Pointreau Y, Rolland F, Alfonsi M, Baudoux A, Sire C, de Raucourt D, Malard O, Degardin M, Tuchais C, Blot E, Rives M, Reyt E, Tourani JM, Geoffrois L, Peyrade F, Guichard F, Chevalier D, Babin E, Lang P, Janot F, Calais G, Garaud $\mathrm{P}$ and Bardet E: Induction chemotherapy followed by either chemoradiotherapy or bioradiotherapy for larynx preservation: The TREMPLIN randomized phase II study. J Clin Oncol 31(7): 853-859, 2013. PMID: 23341517. DOI: 10.1200/ JCO.2012.42.3988.

12 Geoffrois L, Martin L, De Raucourt D, Sun XS, Tao Y, Maingon P, Buffet J, Pointreau Y, Sire C, Tuchais C, Babin E, Coutte A, Rolland F, Kaminsky MC, Alfonsi M, Lapeyre M, Saliou M, Lafond C, Jadaud E, Gery B, Zawadi A, Tourani JM, Khoury C, Henry AR, Hasbini A, Guichard F, Borel C, Meert N, Guillet P, Calais $\mathrm{MH}$, Garaud $\mathrm{P}$ and Bourhis $\mathrm{J}$ : Induction chemotherapy followed by cetuximab radiotherapy is not superior to concurrent chemoradiotherapy for head and neck carcinomas: Results of the GORTEC 2007-02 phase III randomized trial. J Clin Oncol 36(1): 3077-3083, 2018. PMID: 30016178. DOI: 10.1200/ JCO.2017.76.2591

13 Worden FP, Kumar B, Lee JS, Wolf GT, Cordell KG, Taylor JM, Urba SG, Eisbruch A, Teknos TN, Chepeha DB, Prince ME, Tsien CI, D'Silva NJ, Yang K, Kurnit DM, Mason HL, Miller TH, Wallace NE, Bradford CR and Carey TE: Chemoselection as a strategy for organ preservation in advanced oropharynx cancer: Response and survival positively associated with HPV 16 copy number. J Clin Oncol 26(19): 3138-3146, 2008. PMID: 18474879. DOI: 10.1200/JCO.2007.12.7597.
14 Sun Y, Li WF, Chen NY, Zhang N, Hu GQ, Xie FY, Sun Y, Chen XZ, Li JG, Zhu XD, Hu CS, Xu XY, Chen YY, Hu WH, Guo L, Mo HY, Chen L, Mao YP, Sun R, Ai P, Liang SB, Long GX, Zheng BM, Feng XL, Gong XC, Li L, Shen CY, Xu JY, Guo Y, Chen YM, Zhang F, Lin L, Tang LL, Liu MZ and Ma J: Induction chemotherapy plus concurrent chemoradiotherapy versus concurrent chemoradiotherapy alone in locoregionally advanced nasopharyngeal carcinoma: A phase 3, multicentre, randomised controlled trial. Lancet Oncol 17(11): 1509-1520, 2016. PMID: 27686945. DOI: 10.1016/S1470-2045(16)30410-7.

15 Marur S, Li S, Cmelak AJ, Gillison ML, Zhao WJ, Ferris RL, Westra WH, Gilbert J, Bauman JE, Wagner LI, Trevarthen DR, Balkrishna J, Murphy BA, Agrawal N, Colevas AD, Chung $\mathrm{CH}$ and Burtness B: E1308: Phase II trial of induction chemotherapy followed by reduced-dose radiation and weekly cetuximab in patients with HPVassociated resectable squamous cell carcinoma of the oropharynx ECOG-ACRIN Cancer Research Group. J Clin Oncol 35(5): 490497, 2017. PMID: 28029303. DOI: 10.1200/JCO.2016.68.3300.

16 Dietz A, Wichmann G, Kuhnt T, Pfreundner L, Hagen R, Scheich M, Kölbl O, Hautmann MG, Strutz J, Schreiber F, Bockmühl U, Schilling V, Feyer P, de Wit M, Maschmeyer G, Jungehülsing M, Schroeder U, Wollenberg B, Sittel C, Münter M, Lenarz T, Klussmann JP, Guntinas-Lichius O, Rudack C, Eich HT, Foerg T, Preyer S, Westhofen M, Welkoborsky HJ, Esser D, Thurnher D, Remmert S, Sudhoff H, Görner M, Bünzel J, Budach V, Held S, Knödler M, Lordick F, Wiegand S, Vogel $\mathrm{K}$, Boehm A, Flentje M and Keilholz U: Induction chemotherapy (IC) followed by radiotherapy (RT) versus cetuximab plus IC and RT in advanced laryngeal/hypopharyngeal cancer resectable only by total laryngectomy - Final results of the larynx organ preservation trial DeLOS-II. Ann Oncol 29(10): 2105-2114, 2018. PMID: 30412221. DOI: 10.1093/annonc/mdy332.

17 Semrau S, Haderlein M, Schmidt D, Lell M, Wolf W, Waldfahrer F, Uder M, Iro H, Kuwert $T$ and Fietkau R: Single-cycle induction chemotherapy followed by chemoradiotherapy or surgery in patients with head and neck cancer: What are the best predictors of remission and prognosis? Cancer 121(8): 12141222, 2015. PMID: 25537381. DOI: 10.1002/cncr.29188. 